\title{
Taste and Texture of Abalone Meat after Extended Cooking
}

\author{
Keiko Hatae, ${ }^{* 1}$ Hitomi Nakai, ${ }^{* 1}$ Chie Tanaka, ${ }^{* 1}$ \\ Atsuko Shimada, ${ }^{* 1}$ and Shugo Watabe ${ }^{* 2}$ \\ ${ }^{*}$ Department of Nutrition and Food Science, Ochanomizu University, Otsuka, \\ Bunkyo, Tokyo 112, Japan \\ ${ }^{*}$ Laboratory of Marine Biochemistry, Faculty of Agriculture, \\ University of Tokyo, Yayoi, Bunkyo, Tokyo 113, Japan
}

(Received November 24, 1995)

\begin{abstract}
Abalone meat was cooked for $0,15,30,60,180$, and $360 \mathrm{~min}$, and changes in the taste and texture during cooking were studied. During cooking, the weight of meat decreased, and it was $65 \%$ of the original weight after cooking for $360 \mathrm{~min}$. Collagen content in the meat decreased with a concomitant decrease in the hardness of meat $(r=0.82)$. The amount of adenosine 5 -monophosphate increased after cooking for $15 \mathrm{~min}$ and leveled off. The total amount of free amino acids increased after 15-30 min, then decreased. On the contrary, the amount of oligopeptide-bound amino acids kept increasing until $360 \mathrm{~min}$, both in the cooked meat and the drip. In the dominant amino acids of the oligopeptides, collagen constituents amino acids such as glycine, hydroxyproline, and proline were included. By the sensory test, the characteristic abalone taste and odor became stronger as the cooking time increased. This might be the reason why Japanese cookbooks recommend cooking for an extended period such as 15 or $180 \mathrm{~min}$.
\end{abstract}

Key words: abalone, cook, taste, texture, collagen, amino acid, oligopeptide, sensory test

Abalone is a popular delicacy all over the world. When eaten cooked, the cooking time is recommended in Japanese cookbooks to be $15-30$ min or 3-5 h. ${ }^{1,2)}$ The latter cooking period is unusually long compared to those of other marine foods.

Generally, the tough portion of beef meat such as crura is recommended to be cooked in water for a long time. During such cooking, collagen in the connective tissue is converted to gelatin and the meat becomes tender. However, no such examples of cooking for a long time in marine foods other than abalone have been reported.

The temperature at which collagen fiber in mammalian meat shrinks is about $60^{\circ} \mathrm{C}$ or more. ${ }^{3)}$ On the other hand, the collagen in marine foods is known to be more susceptible to heat denaturation. The shrinkage temperature of fish skin collagen is generally about $20^{\circ} \mathrm{C}$ lower than that of mammalian hide collagen. ${ }^{4}$ There has been no study on the shrinkage temperature of abalone collagen so far. Only Kimura and Kubota ${ }^{5}$ reported the denaturation temperature $\left(T_{D}\right)$, which was $28^{\circ} \mathrm{C}$ at $\mathrm{pH} 7$. The $T_{D}$ values of molluscan collagens such as from lobster, blue crab, squid, and pearl oyster ranged from $27.4-33.6^{\circ} \mathrm{C}$ and the shrinkage temperatures $\left(T_{S}\right)$ of the same species were 49 $58^{\circ} \mathrm{C} .{ }^{\circ}$

Kimura and Kubota ${ }^{5}$ claimed that the $T_{D}$ of abalone collagen was lower than that of fish vertebrates because abalone contained less glycine-proline-alanine and glycine-proline-hydroxyproline triplets in the collagen fibers. Raw abalone is very tough, however, and boiling for 1 hour converted $54-56 \%$ of collagen to gelatin. ${ }^{7}$ Therefore, cooking for such a long time is perhaps not needed if only to make the abalone meat tender.

We therefore studied the textural and taste changes in abalone meat during cooking and examined why an extended cooking time is recommended.

\section{Materials and Methods}

\section{Abalone}

Haliotis discus, 350-380 $\mathrm{g}$ of total weight including shell, were collected in October near the Kanagawa Prefectural Fisheries Experimental Station, as in the previous work ${ }^{8}{ }^{8}$ Live specimens were transported to the laboratory. They were shelled and divided into two parts. Each of them was vacuum-sealed in a polypropylene bag and boiled for $15,30,60,180$ or $360 \mathrm{~min}$. The temperature of the central part of the meat rose to $98^{\circ} \mathrm{C}$ after boiling for $12-13 \mathrm{~min}$.

After cooling for $30 \mathrm{~min}$ at room temperature, a middle part of the abalone meat was used as a sample for the experiments. The uncooked abalone was used as a control.

\section{Weight}

The ratio (\%) of the weight of abalone samples after cooking to that before cooking was obtained.

\section{Moisture and Crude Protein}

Moisture was measured by drying muscle tissue in moisture plates at $100-105^{\circ} \mathrm{C}$ to constant weight. Crude protein was determined by the micro-Kjeldahl method.

\section{Collagen}

The abalone sample $(0.1 \mathrm{~g})$ was hydrolyzed and hydroxyproline content was determined using a Hitachi 835S amino acid analyzer as in the previous work ${ }^{8}{ }^{8}$ Collagen content was calculated on the assumption that the hydroxypro- 
line content in abalone collagen is $10.2 \%$ by weight $^{5)}$ and MacFarlane. ${ }^{9)}$ shown as a ratio of the total protein.

\section{Adenosine S'-triphosphate (ATP) and ATP-related Com- pounds}

The abalone sample $(5 \mathrm{~g})$ was homogenized with $10 \%$ perchloric acid $(10 \mathrm{~m} l)$ and centrifuged at $10,000 \times g$ for $15 \mathrm{~min}$, and the resulting supernatant adjusted to $\mathrm{pH} 7.0$ with concentrated KOH. ATP and ATP related compounds were analyzed using a Shimadzu HPLC A-10A (Shimadzu Co., Tokyo) with an Asahipak GS-320H column (Asahikasei Co., Tokyo) under the same conditions as in the previous work. ${ }^{8)}$

\section{Free Amino Acids and Oligopeptides}

With $10 \%$ trichloroacetic acid $(10 \mathrm{~m} /)$, the abalone sample $(5 \mathrm{~g})$ was homogenized, followed by centrifugation at $10,000 \times \mathrm{g}$. Free amino acid and peptide-bound amino acid contents were analyzed using a Hitachi amino acid analyzer $835 \mathrm{~S}$ (Hitachi Co., Tokyo) as in our previous work. ${ }^{8}$ ) Drips in a polypropylene bag were also analyzed. Amino acid contents of extracts and drips were calculated to the value of the original (uncooked) weight of $100 \mathrm{~g}$.

\section{Textural Property}

Changes in the textural property were evaluated by the breaking stress measured with a Rheoner RE-3305 (Yamaden Co., Tokyo). Abalone samples were sliced in the vertical direction into $4 \mathrm{~mm}$-thick pieces and subjected to time-force measurements. From the time-deformation curve, the breaking stress $(\mathrm{P} \mathrm{Pa})$ was calculated as follows:

$$
\mathrm{P}=(\mathrm{B} \times 98) / \mathrm{S}
$$

where $B$ is the maximum force $(\mathrm{g}), \mathrm{S}$ is the base area of the plunger $\left(0.01 \pi \mathrm{cm}^{2}\right)$ and 98 is the acceleration due to gravity $(\mathrm{Pa})$.

\section{Sensory Test}

Panel members were asked to rank the strength of odor, hardness and elasticity of three samples (control, 30-, and 180 -min-cooked samples). They ranked also preferences of odor and overall textural acceptability.

To rank the strength of "umami' and body of the taste, and overall taste acceptability of abalone, abalone samples were cut into $5 \mathrm{~mm}$ pieces and served to panel members to avoid textural sensation affecting the taste judgment.

Panel members tested three samples in individual booths under a red light. The panel was composed of $20 \mathrm{fe}-$ male students and laboratory staff of the Cookery Science Laboratory at Ochanomizu University. Significance levels of ranked data were analyzed by the method of Newell and

\section{Results and Discussion}

\section{Weight and Moisture and Protein Contents}

During cooking, abalone shrank, lost water and watersoluble components as drip, and decreased in weight. After cooking for $360 \mathrm{~min}$, the weight was only $60 \%$ of the original weight (Table 1). When the cooking time was extended, the moisture content decreased due to the production of drips. The protein content showed no significant difference.

\section{Texture}

The breaking stress of abalone samples rapidly decreased after cooking for $15 \mathrm{~min}$ (Fig. 1). When the cooking period was prolonged to 180 or $360 \mathrm{~min}$, abalone meat became even tenderer.

The collagen contents, determined in the same samples to those used for the measurements of breaking stress, also decreased during cooking (Fig. 1). The longer the cooking period, the lower the collagen content in the meat. The change in the collagen content agreed with that of the breaking stress value. In many fish dorsal meats, collagen content is very low at less than $4 \%$ of protein. No relation between the collagen content and firmness after cooking was found. ${ }^{10)}$ In abalone, collagen content is high and we

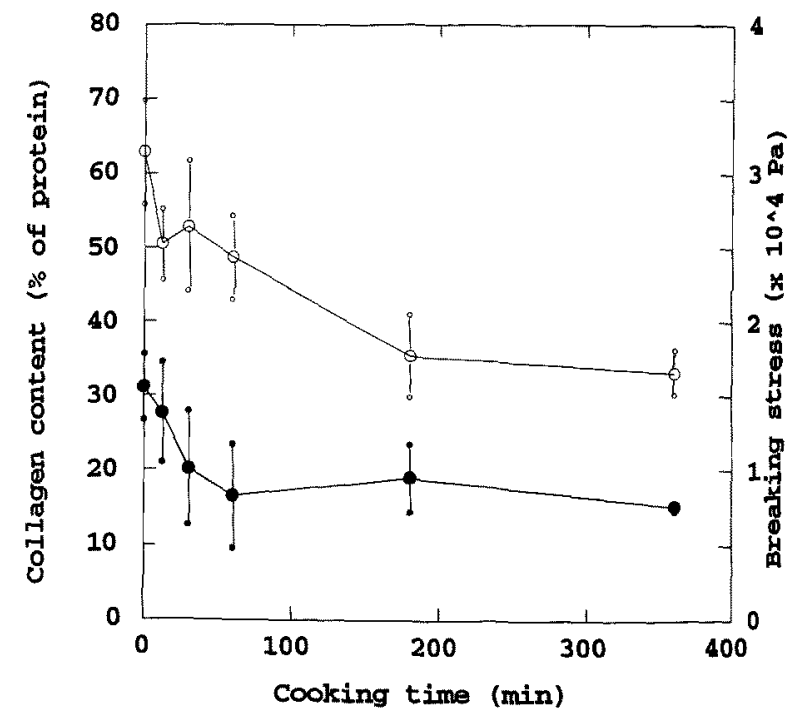

Fig. 1. Cooking-period dependence of the breaking stress and collagen content of abalone meat.

$\bullet-$ : collagen content: $\bigcirc-0$ : breaking stress.

Table 1. Changes in the weight, and moisture and protein content during cooking of abalone meat

\begin{tabular}{|c|c|c|c|c|c|c|}
\hline \multirow{2}{*}{ Constituents } & \multicolumn{6}{|c|}{ Cooking period (min) } \\
\hline & 0 & 15 & 30 & 60 & 180 & 360 \\
\hline $\begin{array}{l}\text { Weight (\%) } \\
\text { Moisture (\%) } \\
\text { Protein (\%) }\end{array}$ & $\begin{array}{c}100.00 \pm 0.00^{\mathrm{a}} \\
77.46 \pm 0.54^{3} \\
14.84 \pm 0.46\end{array}$ & $\begin{array}{l}81.92 \pm 1.63^{\mathrm{ab}} \\
72.37 \pm 0.74^{a b} \\
14.11 \pm 3.79\end{array}$ & $\begin{array}{l}75.64 \pm 7.32^{\mathrm{bc}} \\
72.91 \pm 1.73^{\mathrm{ab}} \\
18.63 \pm 0.43\end{array}$ & $\begin{array}{l}79.08 \pm 2.94^{\mathrm{bc}} \\
72.95 \pm 1.19^{\mathrm{ab}} \\
18.38 \pm 3.13\end{array}$ & $\begin{array}{l}74.08 \pm 5.10^{\mathrm{bc}} \\
69.92 \pm 1.15^{\mathrm{bc}} \\
15.69 \pm 1.29\end{array}$ & $\begin{array}{l}61.18 \pm 4.97^{\mathrm{c}} \\
69.92 \pm 2.80^{\mathrm{bc}} \\
17.89 \pm 2.44\end{array}$ \\
\hline
\end{tabular}

a.b,c Means in the same row with different superscripts are different $(p<0.01)$. 
found that the seasonal change in collagen content was accompanied with a textural change. ${ }^{8,11)}$ Even when the meat was cooked, a correlation ( $r=0.82$ ) between the collagen content and the texture was also found. It has been reported that heat-induced tendering of turban shell muscle was due to the conversion of collagen into gelatin. ${ }^{12)}$ Olley and Thrower ${ }^{7}$ reported that boiling abalone meat for one hour converted collagen to gelatin. Further investigation is required to assess which factor, loss of collagen or gelatinization, contributes more to the tendering of gastropod muscles during cooking.

Abalone meat was very tender after cooking for a long time. From the breaking stress value, $180 \mathrm{~min}$ seems to be sufficient to make abalone meat the tenderest. Thus, we cannot explain the reason why cooking for such a long time as up to $300 \mathrm{~min}$ is suggested in cookbooks to obtain sufficient textural change.

\section{Chemical Components Related to Taste}

After cooking for $15 \mathrm{~min}$, ATP in the abalone extract almost completely diminished. In contrast, the AMP level rapidly increased during this time (Table 2). IMP (inosine5 '-monophosphate), which is known to be a cue of " $u$ mami' taste substances, was not found in the cooked abalone just like in the raw abalone. AMP enhances an "umami" taste by synergism with glutamic acid. ${ }^{13)}$ Therefore, we assumed that the "umami" taste in abalone could increase after cooking due to the production of AMP as in the case of cooking kuruma prawn. ${ }^{14-16}$

Changes in the total amount of free amino acids and oligopeptides in the abalone meat extracts during cooking are shown in Fig. 2 together with those of drips. During cooking, the meat shrank and squeezed drips. The total amount of free amino acids in the meat extract increased after cooking for a short period such as 15 and $30 \mathrm{~min}$, then gradually decreased. Such increase of the total amount of free amino acids may explain the recommendation by Japanese cookbooks of cooking abalone meat for a short period, 15-30 min, together with a rapid accumulation of AMP and immediate decrease of breaking stress during this period. Major components were taurine, arginine, alanine, glutamic acid, and glycine. Changes in these components during cooking were similar to those in the total amount (Fig. 3), though the total amount of free amino acids in the drip increased. The major amino acids in the drip were the same as those in the meat extract, i.e., taurine, arginine, alanine, glutamic acid, and glycine (data

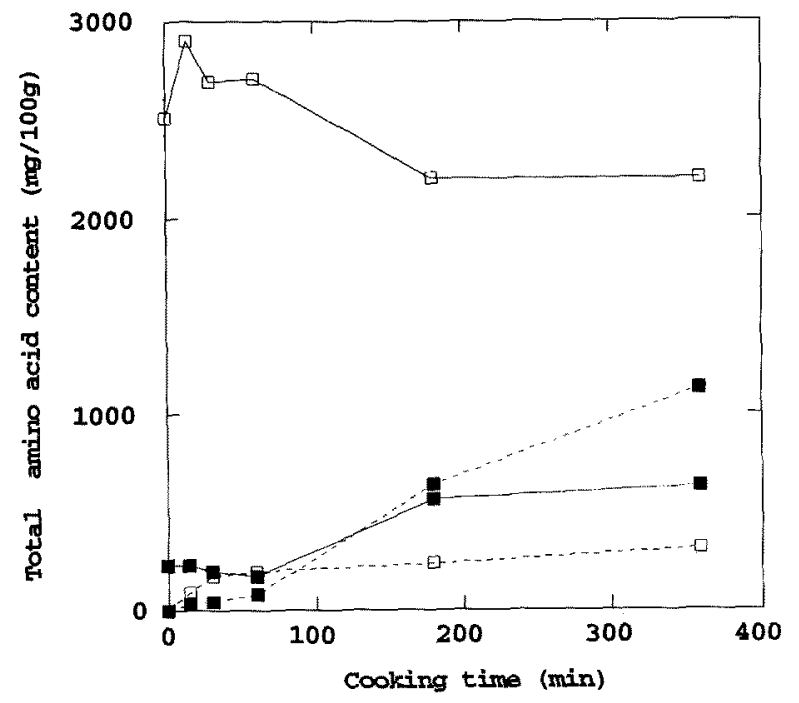

Fig. 2. Changes in the total amino acid content of abalone meat and the drip during cooking.

$\square-\square:$ total amino acid in the meat; $\square--\square:$ total amino acid in the drip; - : total oligopeptide-bound amino acid in the meat; - : total oligopeptide-bound amino acid in the drip.

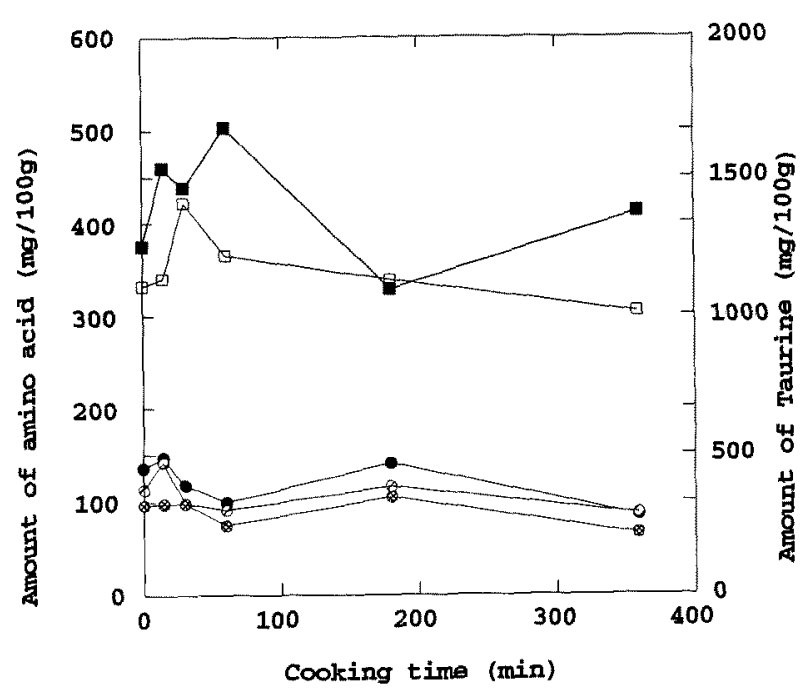

Fig. 3. Changes in the amount of free amino acids in abalone meat during cooking.

- - : taurine; $\square-\square:$ arginine; $\bullet-$ : alanine, - : glutamic acid; - glycine.

Table 2. Changes in the amount $(\mu \mathrm{mol} / \mathrm{g})$ of ATP and its related compounds during cooking of abalone meat

(mean \pm S.D.)

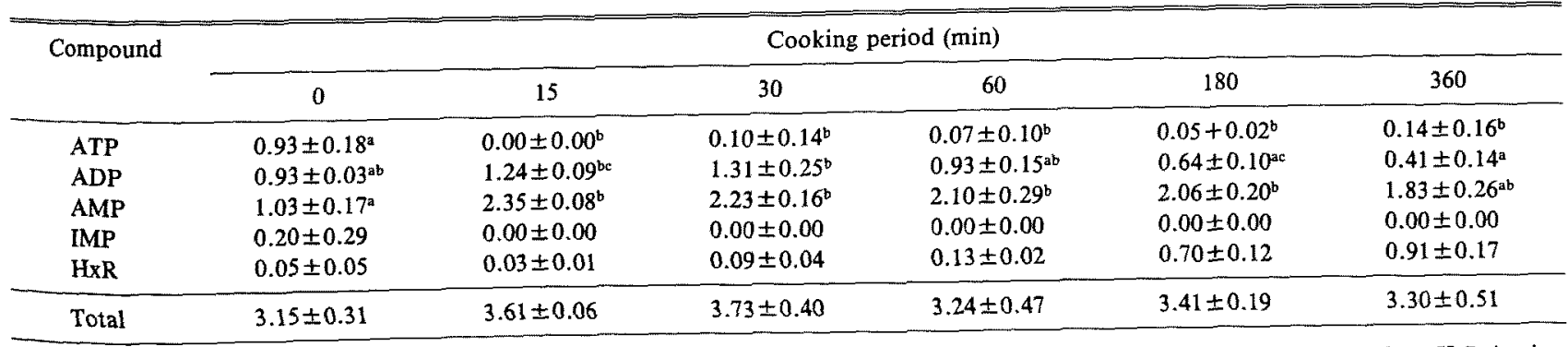

Abbreviations: ATP, adenosine 5'-triphosphate; ADP, adenosine 5'-diphosphate; AMP, adenosine 5'-monophosphate; IMP, inosine 5'-monophosphate: HxR, inosine.

$4, b, c$ Means in the same row with different superscripts are different $(p<0.01)$. 
not shown).

The total amount of oligopeptides in the meat extracts hardly changed during cooking for a short time, but increased after cooking for $180 \mathrm{~min}$ (Fig. 2). The total amount of oligopeptides in the drip increased slowly during cooking for $60 \mathrm{~min}$ then relatively rapidly up to 180 min (Fig. 2).

The changes in the free amino acids and oligopeptides during cooking are described as follows.

The temperature in the center of the abalone meat reached $98^{\circ} \mathrm{C}$ after cooking for $15 \mathrm{~min}$. During this period, the proteolytic enzymes were activated, and decompositions from proteins to peptides and from peptides to free amino acids proceeded. Incubation of beef meat at $40-80^{\circ} \mathrm{C}$ resulted in an increase of the total amounts of free amino acids and oligopeptide-bound amino acids. ${ }^{17)}$ In the early stage of cooking, the rate of peptide production might be equal to that of peptide decomposition, thus the total amount of free amino acids increased and that of oligopeptides remained almost constant. During cooking for a long period, production of oligopeptides might be dominant. However, during this period, it is unlikely that the enzymatic reaction was still proceeding. There is a possibility that the proteolytic reaction in the early stage of cooking made targeted proteins somewhat susceptible to heat decomposition afterward.

The dominant amino acids in the oligopeptides were glutamine plus glutamic acid, glycine, asparagine plus aspartic acid, hydroxyproline and proline (Fig. 4). Among them, glycine, hydroxyproline and proline are the major amino acid constituents in collagen. Sugita et al ${ }^{18)}$ reported that during heat treatment of insoluble collagen of pig skin in water, the breaking of peptide bonds was observed in disc electrophoretic patterns and Sepharose 4B gel filtration patterns. Therefore, one of the main sources of oligopeptides could be collagen.

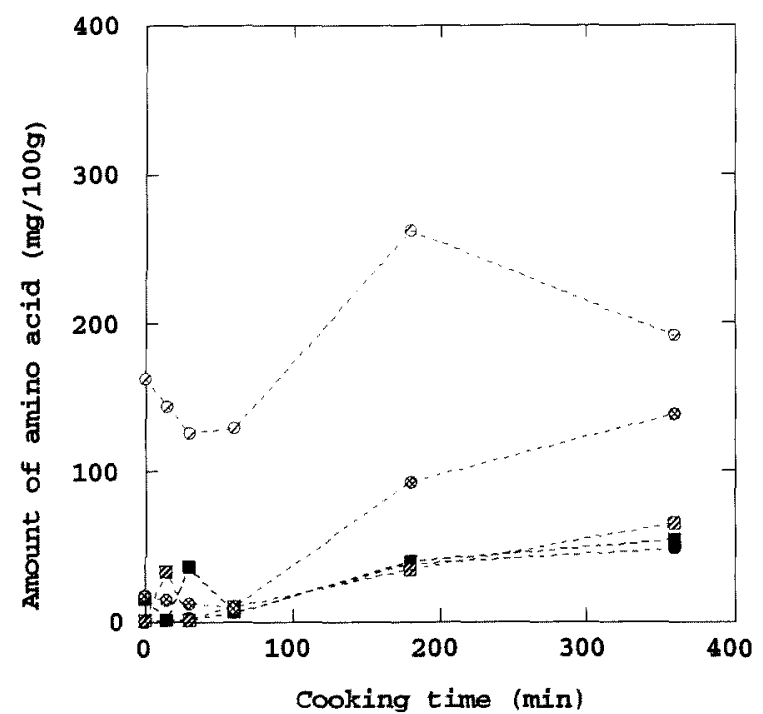

Fig. 4. Changes in the amount of oligopeptide-bound amino acids in abalone meat during cooking.

$\odot-\vartheta$ : glutamic acid + glutamine; - glycine; line; --- : aspartic acid + asparagine; $\bullet--$ : hydroxyproline.
Table 3. Rank sum of the sensory test for abalone meat

\begin{tabular}{llll}
\hline & \multicolumn{3}{c}{ Cooking time (min) } \\
\cline { 2 - 4 } Article & 0 & 30 & 180 \\
\hline Strength of the odor & $60^{\mathrm{c}}$ & $39^{\mathrm{b}}$ & $21^{\mathrm{a}}$ \\
Preference of the odor & $59^{\mathrm{b}}$ & $35^{\mathrm{a}}$ & $26^{\mathrm{a}}$ \\
Hardness of meat & $20^{\mathrm{a}}$ & $41^{\mathrm{b}}$ & $59^{\mathrm{c}}$ \\
Elasticity of meat & $60^{\mathrm{b}}$ & $33^{\mathrm{a}}$ & $27^{\mathrm{a}}$ \\
Preference of the texture & $59^{\mathrm{b}}$ & $32^{\mathrm{a}}$ & $29^{\mathrm{a}}$ \\
\hline "umami" taste & $58^{\mathrm{c}}$ & $40^{\mathrm{b}}$ & $22^{\mathrm{a}}$ \\
Body of the taste & $58^{\mathrm{c}}$ & $39^{\mathrm{b}}$ & $23^{\mathrm{a}}$ \\
Preference of the taste & $58^{\mathrm{c}}$ & $39^{\mathrm{b}}$ & $23^{\mathrm{a}}$ \\
\hline
\end{tabular}

a,b,c Rank sums in the same Iow with different superscripts are different $(p<0.01)$

\section{Sensory Test}

The changes in the amounts of chemical components that we found might affect the taste. To determine why abalone is cooked for an extremely long period, sensory analysis was carried out.

The result of a rank sum test for three abalone samples is shown in Table 3. The raw abalone meat was very tough and not elastic. The hardness decreased when the cooking period was prolonged. From the result of elasticity and overall textural acceptability, $30 \mathrm{~min}$ was thought to be enough for cooking abalone meat. However, the strength of the order and hardness of meat further changed during cooking between 30 and $180 \mathrm{~min}$. It should be noted that the breaking stress decreased during this period (see Fig. 1). In addition, the "umami" taste, body, and overall taste acceptability were improved when the abalone was cooked for $180 \mathrm{~min}$ compared to cooking for $30 \mathrm{~min}$. Panel members felt that the characteristic abalone taste and flavor were stronger in the sample cooked for $180 \mathrm{~min}$ than in that cooked for $30 \mathrm{~min}$. This change in the taste might be related to the increase in the amounts of oligopeptides.

Thus, we conclude that abalone is cooked for a long period not only to make it tender but also to produce its characteristic taste and flavor. Moreover, such a long cooking time for abalone makes the soup consisting of drips tasty.

\section{References}

1) K. Gotoh: Nippon no awabi. Senmon-Ryori, (August), ShibataShoten, Tokyo, 1994, p. 53 (in Japanese).

2) K. Hatano: Awabi no nimono, in "Nihon-Ryori Gijutsu Taikei", Vol. 6, (ed. by K. Abe), Japan Art, Tokyo, 1994, p. 38 (in Japanese).

3) H. R. Cross: 1986. Sensory quality of meat, in" Muscle as food" (ed. by P. E. Bechtel), Academic Press, New York, 1986, p. 291.

4) M. Kubota: Stroma protein, in "Fish Protein", (ed. by Nippon Suisan Gakkai), Koseisha-Koseikaku. Tokyo, 1977, pp. 59 (in Japanese),

5) S. Kimura and M. Kubota: Some properties of collagen from the abalone., 34, 925-929 (1994)

6) Z. E. Sikorski, D. N. Scott, and D. H. Buisson: The role of collagen in the quality and processing of fish. CRC Crit. Rev. Food Sci. Nutr., 20, 301-343 (1985).

7) J. Olley and S. J. Thrower: Abalone-an esoteric food. Adv. Food Res., 23, 143-186 (1977).

8) K. Hatae, H. Nakai, A. Shimada, T. Murakami, K. Takada, Y. Shirojo, and S. Watabe: Abalone (Haliotis discus): Seasonal varia- 
tions in chemical composition and textural properties. J. Food Sci. $60,32-35$ \& 39, (1995).

9) G. W. Newell and J. D. MacFarlane: Expanded tables for multiple comparison procedures in the analysis of ranked data. J. Food Sci., 52, 1721-1725 (1987).

10) K. Hatae, A. Tobimatsu, M. Takeyama, and J. J. Matsumoto: Contribution of the connective tissues on the texture difference of various fish species. Nippon Suisan Gakkaishi, 52, 2001-2007 (1986).

11) R. P. Olaechea, H. Ushio, S. Watabe, K. Takada, and K. Hatae: Toughness and collagen content of abalone muscles. Biosci. Biotech. Biochem., 57, 6-11 (1993).

12) Y. Ochiai, Y. Kariya S. Watabe, and K. Hashimoto: Heat-induced tendering of turban shell (Batillus cornutus) muscle. J. Food Sci., 50, 981-984 (1985).

13) S. Konosu: Taste of fish and shellfish with special deference to tasteproducing substances. Nippon Shokuhin Kogyo Gakkaishi, 20, 432 (1973).

14) S. Fuke, K. Watanabe, and S. Konosu: Enhancing effect of nucleo- tides on sweetness of heated prawn muscle, in "Olfaction and taste XI"' (ed. by K. Kurihara, N. Suzuki and H. Ogawa), Springer-Verlag. Tokyo 1994, pp. 357-360.

15) M. Matsumoto, H. Yamanaka and K. Hatae: Effect of "arai" treatment on the biochemical changes in the kuruma prawn muscle. Nippon Suisan Gakkaishi, 57, 1383-1387 (1991).

16) K. Hatae, H. Tokuda, A. Shimada, M. Matsumoto, and H. Yamanaka: Flavor and texture of "arai" made of kuruma prawn differed in treatment. Nippon Suisan Gakkaishi, 57, 2133-2137 (1991).

17) K. Ishii, M. Tsuchida, T. Nishimura, A. Okitani, A. Nakagawa, K. Hatae, and A. Shimada: Changes in the taste and taste components of beef during heating at a low temperature for a long time. $J$. Home Econ. Jpn., 46, 229-234 (1995).

18) K. Sugita, K. Shirai, K. Wada, and R. Kawamura: Changes of collagen in foods during heating. Part 1 . Solubilization of pig skin collagen. Nippon Shokuhin Kogyo Gakkaishi, 24, 311-315 (1977). 